\title{
"Las Instituciones Funcionan": La falta de diálogo constitucional en Chile, **
}

\author{
JORGE CONTESSE SINGH*** \\ UNIVERSIDAD DIEGO PORTALES
}

Resumen: En los últimos años se ha hecho un lugar común la comprensión de que es sano para la democracia el que actores políticos eviten comentar decisiones judiciales. Tal entendimiento, sostiene el autor, es normativamente indeseable y políticamente dañino. Tomando los casos de la "píldora del día después", revisa cómo es que en Chile los actores institucionales parecen disfrazar los argumentos constitucionales sustantivos que sus pares no institucionales elaboran, haciéndolos pasar por meras discusiones formales. Esta situación, sigue, debilita la práctica constitucional y fomenta una actitud de consenso forzado. Si dicha práctica ha de reclamar consistencia, entonces es preciso incluir con especial fuerza normativa las construcciones de significado constitucional que actores sociales emprenden cuando, por ejemplo, litigan ante las Cortes.

Palabras clave: Derechos fundamentales, interpretación constitucional, relación entre poderes del Estado, cultura constitucional.

Abstract: In the last years it has done a common understanding that is healthy for the democracy that the political actors avoid comments about judicial decision. Such undestanding is normative undesirable and politically harmful. Taking the cases of the "pill of the day after" < Levonorgestrel>, the author reviews how in Chile the institutional actors seems to disguise the sustantives constitucionals arguments that his non institutionals pairs elaborate, making pass them as mere formal discussions. This situation, He sustains, it debilitates the constitucional practice and foments a enforced consensus actitude. If aforementioned practice have to claim consistency, then is precise to include with special normative force the constitutional meaning construtions that social actors undertake when, for example, ligitate in front the courts.

Keywords: Fundamental Rights, Constitutional Interpretation, Relation between the powers of the State, Constitutional Culture.

Son innumerables las veces en que escuchamos a altas autoridades (o personajes públicos que aspiran a serlo) repetir, como dogma de fe, que no se debe comentar los fallos judiciales. Esta actitud, suele decirse, es muestra de respeto por la independencia judicial y de compromiso con el estado de

\footnotetext{
* Versión escrita de la presentación del profesor Contesse en el II Congreso Estudiantil de Derecho y Teoría Constitucional.

** Estoy en deuda por las valiosas sugerencias y críticas hechas a una versión preliminar de este trabajo por Roberto Gargarella, Domingo Lovera y Robert Post. Agradezco también los comentarios hechos por Fernando Atria en el panel donde se presentó originalmente este artículo. Los posibles errores e imprecisiones que han quedado, obviamente, son míos.

*** Profesor de la Facultad de Derecho de la Universidad Diego Portales.
} 
derecho. Si la labor de los jueces consiste en resolver conforme a derecho, entonces las opiniones políticas del trabajo judicial no son bienvenidas. Quien critica al Poder Judicial por el trabajo que desempeña no tiene, por así decirlo, credenciales democráticas. "Yo no comento las decisiones judiciales" es posiblemente una de las expresiones que, sin mucha reflexión, se ha convertido en lugar común de nuestra práctica política. En apariencia una muestra de civilidad y respeto por el reparto de competencias estatales, esta retórica, sin embargo, poco sirve al desarrollo de una cultura política robusta, en la cual se encuentren y puedan medirse las voces disonantes que vienen tanto de la diluida sociedad civil -O 'cuerpos intermedios', en la jerga de la Constitución vigente- como de actores estatales. Ciudadanos y funcionarios viven, piensan y creen en cuestiones constitucionales. De éstas, muchas pasan por los tribunales de justicia, los que "inexcusablemente" -así también dice la Constitución- deben conocerlas, resolverlas y, como si ello no bastara, hacer ejecutar lo resuelto.

En el siguiente trabajo presento una descripción de la falta de diálogo que se da entre los actores institucionales y sociales - a la hora de determinar el significado constitucional de situaciones que reclaman respuestas jurídicas- como una situación que debe combatirse. El análisis lo emprendo basado en el debate constitucional que en Estados Unidos pone énfasis en las actitudes que los diversos actores relevantes mantienen hacia dichas situaciones de hecho. Para ello, en primer lugar, describo de manera breve esta discusión académica, y sugiero de qué manera puede ella ilustrar algunos problemas también presentes en la práctica constitucional chilena (I). En seguida, examino los arreglos institucionales y políticos (no explícitos) que han determinado una suerte de aversión por la diferencia y el disenso en Chile. Entre los primeros, destaca el sistema de elección parlamentaria diseñado a fines de la dictadura militar; entre los segundos, resalta la denominada "política del consenso" o "democracia de los acuerdos" (II). El examen de estas herramientas de práctica política es útil para situar el contexto en que se produce la aversión al diálogo que quiero analizar. Tras esta vuelta, planteo que en un escenario de alejamiento de las posibilidades de intervención política por parte de grupos sociales como ha ocurrido en el llamado período "de transición a la democracia"-, el Poder Judicial ha ido emergiendo como receptor de demandas no exclusivamente jurídicas, lo que ha originado sus propios problemas (tanto prácticos como normativos) (III). Posteriormente, analizo el caso de la llamada "píldora del día después" no bajo una óptica dogmática, sino interesado en la evidencia que dicho caso exhibe sobre la manera disfrazada con la que se argumenta constitucionalmente -cuando se produce algún intercambio de relevancia constitucional entre ciudadanos y operadores jurídicos, líderes políticos o funcionarios estatales. A tal efecto, examino los dos casos que han llegado a tribunales (uno, un recurso de protección; otro, una demanda de nulidad de derecho público) (IV). Por último, planteo algunas conclusiones. Argumento que en orden a dotar a la práctica constitucional chilena de mayor consistencia, se hace necesario insistir en acortar la brecha entre la cultura constitucional -si existe tal cosa- y el derecho o jurisprudencia constitucional.

\section{Dos escenarios diferentes: ¿dos problemas distintos?}

Como se sabe, la discusión por excelencia en el derecho constitucional estadounidense radica, desde hace larga data, en la incomodidad que resulta de tener una Corte Suprema, compuesta por nueve miembros no elegidos directamente por el pueblo, que se arroga la autoridad de declarar inválidos estatutos legales cuando, según su interpretación, contradicen la Constitución Federal.1 Por más

\footnotetext{
${ }^{1} \mathrm{El}$ asunto arranca con la famosa sentencia que el juez Marshall pronunciara en el caso Marbury v. Madison, en 1803. A pesar de ser una decisión poco feliz por la cuestión de fondo que se discutía y la parcialidad del juez que conocía el asunto, suele resaltarse la elocuencia con la que Marshall inaugura la facultad de revisar judicialmente la constitucionalidad de las leyes -facultad que no contemplaba la Constitución Federal de 1787, y que fuera debatida anteriormente en El Federalista, en particular por Hamilton.
} 
que pasen los años y las decisiones de la Corte sean comentadas hasta el cansancio, el debate no acaba. Al contrario, se revitaliza adquiriendo novedosas formas. La relación que existe entre los poderes del Estado, en particular el del Congreso y el Poder Judicial, busca nuevas formas de entendimiento por parte de académicos de diversas procedencias, y así da origen a debates sobre la misma cuestión pero que adoptan renovados argumentos.

Uno de los últimos giros en la discusión sobre revisión judicial es el emprendido hace más de una década por profesores de derecho y de ciencia política que apelan a la construcción de significado constitucional fuera de la Corte. De diverso modo, estos autores -agrupados bajo la chapa de 'constitucionalismo popular o legislativo'- cuestionan el dogma por cuya virtud se ha de buscar el significado de la Constitución única o preferentemente en las decisiones de la Corte Suprema. En cambio, reclaman, el Congreso, el Presidente y los ciudadanos, en general, también atribuyen significado a la Constitución, por lo cual la interpretación del texto fundamental debe consecuentemente recoger esos (otros) entendimientos constitucionales si dicho texto ha de ser el documento que funda, justifica y permite la convivencia civil de una nación. De no hacerlo, argumentan, difícilmente podría decirse que la Constitución le pertenece al pueblo, y no solo a los nueve jueces sentados en la Corte Suprema.2 La medida y extensión en que las interpretaciones que de la Constitución se hacen fuera de la Corte es, obviamente, objeto de debate y desacuerdo en esta verdadera escuela de pensamiento constitucional. 3

En este debate sobre la extensión de la autoridad que los diversos actores constitucionales tienen para declarar el sentido de la norma superior, se verifica no solo una discusión jurídica, de técnica legal o de dogmática. En ella, como en cualquier debate genuinamente constitucional, la teoría y la práctica política se entrelazan y hacen casi evidente que importan, las dos, mucho. Que en los Estados Unidos, tímidamente desde fines de los ochenta y con renovada fuerza a comienzos de esta década, sectores académicos autodefinidos como 'progresistas' se lancen en contra del monopolio interpretativo de la Corte Suprema no debe extrañar si se acepta la evidente relación que el derecho tiene con la política. En particular, el derecho constitucional. La Corte Suprema estadounidense siempre ha sido un verdadero actor político, sin por ello abdicar de sus credenciales jurídicas. Esta observación, espero, debiera importar para la discusión a emprender en adelante. 4

\footnotetext{
${ }^{2}$ En esta línea militan, entre otros, Larry KRAMER, The People Themselves: Popular Constitutionalism and Judicial Review, New York: Oxford University Press, 2004; Jeremy WALDRON, Law and Disagreement, New York: Oxford University Press, 1999; Mark TUSHNET, Taking the Constitution Away from the Courts, New Jersey: Princeton University Press, 1999; Keith E. WHITTINGTON, Constitutional Construction: Divided Powers and Constitutional Meaning, Cambridge: Harvard University Press, 1999; Robert C. POST y Reva B. SIEGEL, "Legislative Constitutionalism and Section Five Power: Policentric Interpretation of the Family and Medical Leave Act”, en Yale Law Journal Vol. 112, 2003, p. 1943 y ss.; Robert C. POST y Reva B. SIEGEL, "Protecting the Constitution from the People: Juricentric Restrictions on Section Five Power", en Indiana Law Journal, Vol. 78, 2003 p. 1 y ss.; Barry FRIEDMAN, "Mediated Popular Constitutionalism”, en Michigan Law Review Vol. 114, 2003, p. 2596 y ss. Como antecedentes de esta literatura, véase Louis FISHER, Constitutional Dialogues: Interpretation as Political Process, New Jersey: Princeton University Press, 1988, y Paul BREST. "Congress as Constitutional Decisionmaker and its Power to Counter Judicial Doctrine”, en Georgia Law Review Vol. 21, 1986, p. 57 y ss. Desde luego, que académicos identificados con ideas progresistas se agrupen bajo esta metodología de trabajo, no significa que los neo conservadores del derecho constitucional hayan abandonado el interés por la Corte y la revisión judicial. Al respecto, véase Erwin CHEMERINSKY. "In Defense of Judicial Review: The Perils of Popular Constitutionalism”, en U. Ill. L. Rev., Vol. 2004, p. 673 y, con casi los mismos argumentos, Erwin Chemerinsky, "In Defense of Judicial Review: A Reply to Professor Kramer", en Cal. L. Rev. Vol. 92, 2004, p. 1013 y ss.
}

${ }^{3}$ Así, por ejemplo, Tushnet y Kramer rechazan la revisión judicial como parte del sistema legal. POST y Siegel, dentro de la misma línea pero con variaciones, ven en ella la posibilidad de desarrollar valores constitucionales que Kramer no considera correcto ni posible de hacer en el foro judicial. Véase POST, Robert y SIEGEL, Reva. "Popular Constitutionalism, Departmentalism, and Judicial Review", en Calif. L. Rev.Vol. 92, 2004, p. 1027 y ss.

${ }^{4}$ Ante la eventualidad de que alguien interpele esta afirmación blindando al Poder Judicial chileno de la posibilidad de considerarlo como un actor "político", baste citar a uno de los primeros constitucionalistas del país, José Victorino Lastarria. Ya a mediados del siglo XIX, Lastarria sostenía, en sus Elementos de Derecho Público Constitucional, que "[e]l poder judicial es como los demás, un verdadero poder político del Estado, i por consiguiente no puede existir sino en virtud de una delegación nacional, 
Anteriormente, el mismo segmento progresista (aunque con representantes distintos) enarbolaba la acción de la Corte de revisar constitucionalmente las leyes por sus decisiones en favor de sectores postergados, como ha sido, por nombrar algunos, el término de la segregación racial en las escuelas públicas en la década del cincuenta, la férrea protección de la libertad de prensa y del derecho de sufragio de las minorías como mecanismos de participación política, en los sesenta, el respeto por los derechos de autonomía reproductiva, a comienzos de los setenta, o los tímidos pero significativos pronunciamientos a favor de la libertad de autodeterminación sexual de las personas homosexuales. Para quienes han defendido tales agendas sustantivas, la autoridad de la Corte de determinar el significado de la Constitución no solo debe respetarse, sino además, promoverse. Con todo, hoy, con una Corte Suprema que hace gala de posiciones conservadoras, hay quienes naturalmente buscan en otros actores sociales los argumentos constitucionales que permitan mantener los precedentes liberales que arriesgan ser revocados y, aún más, avanzar una agenda progresista a nivel federal. De allí que surja, para muchos, un interés en las interpretaciones que se hacen fuera de la Corte, tanto por actores institucionales como sociales; interés que se transforma en preocupación cuando se está frente a una Corte que muestra poca disposición a considerar el parecer de los demás poderes del Estado.5 Barry Friedman, miembro de esta milicia progresista, no esconde la necesidad de que los constitucionalistas reaccionen ante el curso de la práctica. Para él, la teoría constitucional es "inevitablemente una reacción a lo que ocurre hoy en el derecho constitucional".6

Ahora bien, la comparación entre el sistema constitucional chileno y el de los Estados Unidos arroja, al menos, una primera y fundamental diferencia: el sistema de control constitucional de las leyes en nuestro país no ha estado concentrado en un único tipo de órgano y, el de revisión judicial en sentido estricto, ha sido antes que todo una mera declaración constitucional sin aplicación gravitante. Como es sabido, desde que no existe algo así como una Corte o Consejo Constitucional, el control de las leyes en el país norteamericano está radicado -por causa de un magistrado algo arrogante, valga señalarlo- exclusivamente en jueces que pertenecen al Poder Judicial. Es este Poder el único que, como tribunal, se pronuncia en clave constitucional. En Chile, en cambio, este control se ha ejercido no solo de manera colectiva -la Corte Suprema (cuando tenía dicha atribución) y no jueces individualessino, además, de modo compartido (hasta 2005, con el Tribunal Constitucional).7 Otra diferencia, quizá más importante que la anterior, es que en los Estados Unidos la revisión judicial ha sido profusamente utilizada (dando origen a las disputas, por ejemplo, entre quienes defienden el 'activismo judicial' y quienes se oponen a él). En nuestro país, el solo término "revisión judicial" parece más la traducción de lo que allá ocurre que la descripción de una práctica en que un poder del Estado escruta prolijamente lo que otros hacen.

cuya circunstancia es la única base de su independencia”. LASTARRIA, José Victorino. Elementos de Derecho Público Constitucional. $2^{\mathrm{a}}$ edición, Santiago, Imprenta Chilena, 1848, p. 145.

${ }^{5}$ Quien fuera presidente de la Corte Suprema hasta 2005, William Rehnquist, señaló en más de una ocasión que dicho tribunal es "el expositor último de lo que el texto constitucional ordena" (ver, por ejemplo, United States v. Morrison 529 U.S. 598, 2000). De acuerdo con Post y Siegel, este tipo de afirmaciones son muestra del modelo actual que la Corte tiene para interpretar la Constitución -un modelo que ellos llaman "juricéntrico", en tanto solo admite las visiones legales o "técnicas" que de la Constitución se tenga. Este modelo se opone, según ellos, a uno de carácter "policéntrico", en que importa, además de la opinión técnica o "jurídica” de la Corte, el entendimiento político que los órganos como el Congreso tienen de la Constitución.

${ }^{6}$ FRIEDMAN, Barry. "The Cycles of Constitutional Theory", en 67-Sum Law. \& Contemp. Probs, 2004, pp. 149 y ss. (el énfasis es mío).

${ }^{7}$ Una cuestión distinta de analizar, aunque en la misma línea que aquí planteo, es la coherencia o falta de ella que es posible trazar entre la jurisprudencia del Tribunal Constitucional y aquella emanada de las salas de la Corte Suprema, en especial, de aquellas donde los mismos ministros se sientan. 
Ahora bien, no es solo este aspecto el que interesa cuando se analizan cuestiones constitucionales. Que en Chile la Corte Suprema haya renunciado a su facultad de controlar la ley cuando contraría la Constitución -facultad ahora radicada en el Tribunal Constitucional- no importa que entre nosotros no exista, primero, justicia constitucional y, en seguida (y como causa y efecto de lo anterior), que el ejercicio de la jurisdicción constitucional no sea manifestación de un debate entre diversos actores sobre el significado de las cláusulas constitucionales. Como señalé más atrás, es en esta rama del derecho donde se ve con nitidez que las decisiones institucionales no son solo derecho, sino también política -o, si se prefiere, manifestaciones de "lo político", en el sentido de Mouffe.8 De allí que un análisis de la forma como los poderes del Estado dialogan entre sí -o no dialogan, desde luego- cuando se discute sobre la interpretación de la Constitución sea pertinente. En verdad, parece necesario hacerlo para entender de mejor manera la práctica constitucional que en Chile desarrollamos.

La Constitución vigente tiene un pecado original. No es, genuinamente, una Constitución en el sentido de haber sido forjada por acuerdos (y desacuerdos) que el pueblo entiende necesarios de plasmar en un texto fundamental. Tampoco fue concebida con mecanismos que le permitan con facilidad reconstruir y explicar constitucionalmente el conflicto y la armonía entre los ciudadanos una vez que dicho texto es puesto en ejecución. El propio documento -tal como ha sido aplicado en Chile- ha generado una práctica difícil de asir. Así, por ejemplo, Carlos Peña la describe como "procesalmente avanzada, pero argumentativamente arcaica" 9 , basándose en la jurisprudencia que en materia de recurso de protección alcanza tanto al Estado como a particulares sin que ello haya provocado el debate dogmático o incluso la incomodidad de la comunidad legal que en otras jurisdicciones necesariamente suscita (e.g., Alemania, Sudáfrica o Irlanda). Por su parte, Fernando Atria, comentando a Peña, la ve como "procesalmente avanzada porque es argumentativamente arcaica"10, mientras otros comentaristas insisten en diversas debilidades de ella. En definitiva, parece tratarse de una práctica constitucional que "paraliza la imprescindible deliberación colectiva que permite generar identidades y actitudes sociales responsables"11, impresión que se verifica cuando se examina, como hago a continuación, la paradigmática ausencia de diálogo entre los poderes del Estado cuando se erigen asuntos constitucionales.

En mi análisis examino dos órdenes de cuestiones que parecen relevantes a la hora de comprender la carencia de una cultura de diálogo entre los actores constitucionales. Por una parte, existen dispositivos institucionales que obstaculizan este diálogo que, según diré, es consustancial a un sistema democrático. Entre estos mecanismos, el marcado presidencialismo que existe en el constitucionalismo chileno es clave. La gravitancia que el Ejecutivo tiene en materias constitucionales es, como ha sido puesto de manifiesto por muchos, exagerada. Por otra parte, junto con esta importante dimensión "institucional", la ausencia de diálogo entre actores constitucionales -en particular, entre los poderes públicos, pero también entre éstos y la ciudadanía- ha sido potenciada por una de las características de la denominada "transición a la democracia". Me refiero a la fascinación por el consenso (político) que,

${ }^{8}$ Véase MOUFFE, Chantal. El retorno de lo político. Barcelona, Paidós, 1999 y On the political, New York, Routledge, 2005.

${ }^{9}$ PEÑA GONZÁLEZ, Carlos. Práctica constitucional y derechos fundamentales. Santiago, Corporación de Reparación y Reconciliación, s/f, p. 155.

${ }^{10}$ Según él, “[p7orque es argumentativamente arcaica nuestra práctica constitucional se ha desarrollado más allá de lo prudente sin que nuestros profesores se dieran cuenta de lo que ocurría”. ATRIA L., Fernando. "Revisión judicial: el síndrome de la víctima insatisfecha", en Estudios Públicos, N 79, invierno de 2000, (pp. 347-402), p. 389.

${ }^{11}$ CONTESSE SINGH, Jorge. "Reglas y principios: jjerarquía entre los derechos constitucionales?”, en Sociedad Chilena de Filosofía Jurídica y Social, en Anuario de Filosofía Jurídica y Social, No 20, Valparaíso, 2002, (pp. 53-93), p. 93. Exploro la idea de responsabilidad en la práctica constitucional en CONTESSE SINGH, Jorge. "Responsabilidad por la interpretación constitucional”, en Revista Derecho y Humanidades, No 11, Facultad de Derecho, Univ. de Chile, 2005, pp. 281-294. 
desde el retorno de la democracia en 1989-90, es celebrada transversalmente por los partidos políticos con representación parlamentaria.

El carácter presidencialista de la Constitución de 1980 es un dogma de fe en la dogmática constitucional chilena. Si existe algo así como una tradición constitucional chilena, esta, se dice, ha sido erigida sobre la base de un presidencialismo fuerte. 12 Con todo, se aprecia una actitud poco crítica frente a este hecho, como si el presidencialismo fuera una suerte de factor de desarrollo que no puede ser intervenido. No ha sido la academia chilena, en efecto, la que ha llamado la atención de manera más elocuente sobre las desventajas de un sistema de esta naturaleza. Carlos Nino, por ejemplo, se refiere a esta situación como "hiper-presidencialismo".13 Estudiando el caso chileno, un cientista político estadounidense coincide con estos juicios.14 Según Siavelis, la inversión de los ámbitos de competencia que la Carta del 80 hiciera en materia de reserva legislativa -pasando, como es sabido, de un sistema de reserva legal mínimo a uno de reserva legal máximo- dota al Presidente de la República de un poder excesivo. Se trata, dice, de "una de las atribuciones más importantes que tiene el Presidente en Chile".15 Y, en efecto, estamos habituados a la anomalía técnica de considerar a la figura del Presidente como un órgano 'co-legislador'.

Dicha situación tiene diversas implicaciones, algunas de las cuales este trabajo espera abordar. Examinar la retórica constitucional que emplean (o no emplean) los actores estatales cuando está en juego la disputa sobre el significado de cláusulas constitucionales obliga a mirar, como protagonista estelar, al Ejecutivo. En un régimen en el que la Presidencia no juega el rol determinante que la Constitución de 1980 le asigna, la mirada debiera compartirse con el análisis del comportamiento del Parlamento, que es el lugar donde convergen las diversas fuerzas sociales.16 En este artículo analizo el caso de la llamada "píldora del día después", no tanto por las fascinantes distorsiones técnicas que el caso tiene, sino porque él hace evidente cómo es que el Congreso Nacional, a pesar de sus funciones constitucionales, resulta ser un actor secundario a la hora de entablar (o no) un diálogo con otros actores institucionales o sociales, como el Poder Judicial o la ciudadanía organizada en grupos de interés, respectivamente. Mi propósito es poner en evidencia de qué manera, enfrentados a un caso constitucional -como es la discusión acerca del peso relativo que tienen intereses contrapuestos, e.g., los derechos de autonomía reproductiva de las mujeres y la protección institucional a favor de los sujetos no nacidos- los órganos del Estado y la ciudadanía no logran encontrarse a la hora del debate que dicha cuestión necesariamente suscita. Para algunos, parece tratarse solo de un tema de derechos reproductivos, mientras que otros solo lo ven como un atentado a la vida de los que están por nacer. En medio, hay quienes ni siquiera argumentan en clave de derechos fundamentales -no obstante los reclamos que se escuchan. El asunto, desde luego, podría ser resuelto apelando a cuestiones meramente formales. Si hacemos una analogía con lo que ocurre en el derecho privado, habría, por así decirlo,

12 Véase BRAVO LIRA, Bernardino. De Portales a Pinochet: Gobierno y Régimen de Gobierno en Chile. Santiago, Editorial Jurídica de Chile, 1985.

${ }^{13}$ NINO, Carlos S. La Constitución de la democracia deliberativa. Barcelona, Gedisa, 1997 y "The Debate over Constitutional Reform in Latin America", en Fordham Int'l L.J, Vol. 16, 1992-3, p. 635 y ss.

${ }^{14}$ Véase SIAVELIS, Peter M. The President and Congress in Postauthoritarian Chile: Institutional Constraints to Democratic Consolidation. University Park, Pennsylvania State University Press, 2000. En la misma línea, consúltese LONDREGAN, John B. Legislative institutions and ideology in Chile. Cambridge, Cambridge University Press, 2000.

${ }^{15}$ SIAVELIS, op. cit., p. 16.

${ }^{16}$ SIAVELIS sostiene que "la faceta más importante de una [eventual] reforma institucional en Chile consiste en fortalecer al Congreso Nacional y restaurar la efectividad de su carácter de órgano legislativo, siendo este capaz de representar los distintos partidos y grupos que existen en el espectro político. Un Parlamento vigorizado", sostiene, "permitiría que éste fuese el lugar para el acuerdo y la negociación entre partidos, así como entre los poderes del Estado, tal como ocurría en el pasado". Ibid., p. 193. 
una práctica constitucional que adolece de un vicio del consentimiento similar al error esencial. En este caso, las voluntades constitucionales de los diversos actores que participan del desarrollo de la práctica nunca se topan. Del mismo modo en que quien celebra una donación con quien cree celebrar una compraventa no da origen a una convención, cuando los actores sociales e institucionales renuncian a la posibilidad de dialogar en una misma clave (constitucional) sobre un asunto que reclama diversas posiciones, el desarrollo de la práctica se resiente. Ciertamente, no puede irse tan lejos como para sugerir que ella adolece de una suerte de nulidad absoluta. Pero sí es posible sugerir que la consistencia e integridad de dicha práctica constitucional se debilita.

\section{La "política del consenso" quince años después}

Hacia el final de la dictadura, las fuerzas políticas que negociaron la salida de Pinochet -entre ellas, la Concertación de Partidos por la Democracia, que estaba por comenzar un prolongado período en el poder- acordaron un particular mecanismo por medio del cual se entendió que la gobernabilidad del país estaría asegurada. Esta herramienta, como es normal en toda negociación, generaría réditos para ambas partes ya que los partidos vinculados a la dictadura veían con malos ojos la llegada al Gobierno de personas que no habían sido bien tratadas por el régimen de Pinochet -generando la natural desconfianza de quien sabe que su actuar ha sido, cuando menos, muy reprochable-; y la Concertación, por su parte, necesitaba asegurar que su minado poder civil podría efectivamente contrarrestar la maquinaria militar que seguía instalada institucionalmente.

Como es sabido, esta misma institucionalidad aseguraba la composición (forzada) de dos bloques políticos. El sistema electoral fue diseñado entre el plebiscito de octubre de 1988 -que sacó a Pinochet- y las elecciones presidenciales de diciembre de 1989 -que inauguraron la era de la Concertación-, de modo tal que por un arreglo institucional, y no por voluntad popular, determinados sectores tuvieran asegurada (sobre)representación política en desmedro de otros. El estudio exhaustivo que la ingeniería electoral del régimen de facto hiciera sobre los distritos y circunscripciones del país llevó a la elaboración de fórmulas de elección política que garantizaran que los perdedores no lo fueran tanto. Para algunos, en verdad, que los perdederos simplemente parecieran ganar. A los efectos de este trabajo, denomino a esta fórmula basada en la planificación electoral la herramienta "institucional".

Paralelamente, casi como corolario natural de la estrategia institucional, la Concertación se vio obligada a consensuar una manera de mediar los conflictos reales y eventuales que se generarían como consecuencia de la llegada de la democracia. La dimensión de poder de quienes debían en el papel replegarse era por entonces enorme -lo es aún, para muchos-, cuestión que hacía necesario asegurar posiciones antes que arriesgar proyectos e ilusiones ideológicas. Se reformó la Constitución de 1980 de manera sustantiva, en un proceso de negociación que muchos elevan a categoría de pacto fundacional, dando origen y cuenta de una nueva retórica y práctica política. La aversión por la diferencia era entonces una buena credencial para gobernar un país fracturado por el desacuerdo. Así, se supo de la llamada "política del consenso". De ambos lados del cuadro político -diseñado meticulosamente algún tiempo atrás- se le rindió homenaje a quienes se subían al carro del acuerdo y el entendimiento casi por unanimidad. Parecía que en él viajaría el desarrollo de Chile. De esta manera, si el modelo de elección parlamentaria es la herramienta institucional que dibujara el renacer democrático chileno, la adopción del consenso como directriz de gobernabilidad es la herramienta "política".

La "política del consenso" sirvió, sin duda, para que algunas situaciones y temas pudieren avanzar en la agenda pública. Pero, al mismo tiempo -y auxiliada por el mecanismo institucional de elección parlamentaria- esta forma de hacer política tiñó el entendimiento colectivo de lo que el sistema democrático debe ser. El disenso fue, por medio de estos mecanismos, institucional y políticamente erradicado. El slogan de la diversidad por causa de democracia no alcanzó a tapar la brecha que se fue 
generando entre una ciudadanía ansiosa por recuperar el autogobierno colectivo y una estructura de poder hermética y centralizada. La política del consenso, vista desde afuera, es clave para entender el "éxito de los primeros Gobiernos democráticos de la era post-autoritaria; éxito alcanzado en función del contexto de un proceso democrático que sirvió para acallar el conflicto y para crear un patrón semejante al de un gobierno consociativo de facto".17

No parece aventurado sugerir que tanto el mecanismo institucional como el político distorsionaron las fuerzas sociales que la ciudadanía encarnaba en una época de agitación cívica, en un momento que podría calificarse, de acuerdo con la noción acuñada por Ackerman, como "constitucional".18 Se trataba, en rigor, de determinar el método por el cual los conflictos y desacuerdos serían abordados, lo cual, ya hemos dicho, generaba expectativas muy altas. Lo cierto es que el proceso fue paulatinamente sacando a la gente del medio, dando paso a una estructura de toma de decisiones muy alejada de un ideal democrático - digamos, una persona, un voto. Normativamente, es posible valorar el modo como la comunidad política decide resolver sus conflictos. En esto, es ilustrativo el análisis que emprende Waldron cuando discute el principio de mayoría como modo de adoptar decisiones colectivas. El profesor neozelandés sugiere "una interpretación basada en la idea de consentimiento de la visión lockeana según la cual las decisiones por mayoría son algo natural", señalando que "el consentimiento se da para obligarse por algún tipo u otro de procedimiento de toma de decisiones; el cual bien podría incluir algo menos que la unanimidad".19 Hago énfasis en la palabra "algún" (tipo de procedimiento) toda vez que podría pensarse que la política del consenso fue un modo de adoptar decisiones colectivas legítimamente acordado por quienes gobernarían el país. Aquí, Waldron no argumenta a favor de un tipo específico de procedimiento de toma de decisiones. Con todo, mi segundo énfasis -"algo menos que unanimidad"- sugiere que el procedimiento que se adopta es un mal menor -por cuanto la unanimidad, como advirtiera Locke, "es casi imposible de alcanzar". Si esto es así, la política del consenso adoptada en Chile, si bien satisface eventualmente la primera parte de la cita de Waldron, ciertamente no cumple con la segunda mitad de ella, vale decir, está lejos de ser un sucedáneo del mecanismo de la unanimidad. Y es este "segundo mejor" el que se ha posicionado como el óptimo de nuestra práctica política.

\footnotetext{
17 Ibíd., p. 191. La referencia (no expresa) de Siavelis al trabajo de Arend Lijphart y su modelo de democracia consociativa o consocional tiene sorprendente asidero. En septiembre de 1990, esto es, a pocos meses de reinstalada la democracia en el país, sentados en una mesa redonda organizada por el Centro de Estudios Públicos junto a otros profesores nacionales y extranjeros, el profesor chileno Bernardino Bravo Lira le señala al politólogo de origen holandés que su tesis es especialmente aplicable a la realidad de Iberoamérica, toda vez que aquí, señala Bravo, los gobiernos para ser estables deben ser "eficaces", y el modelo consociativo, dice, es particularmente calificado para lograr tal objetivo. En sus palabras: "[s]e cita al profesor Lijphart frecuentemente porque el sistema consociativo se considera muy afín a nuestra manera de ser. Estoy seguro de que el profesor Lijphart tiene más admiradores de lo que él se imagina entre nosotros. Más aún, muchos que no saben quién es Lijphart están de acuerdo espontáneamente con los planteamientos consocionales, porque responden a su mentalidad, que se inclina a combinar lo electoral con lo gremial, más bien que a desconocer esto último y quedar tan solo con una fachada de sufragios, elecciones y partidos. En resumen, pienso que a la hora de determinar el régimen de gobierno que más conviene a Chile en estos momentos, este criterio de la eficacia debe ser especialmente tomado en cuenta. El más conveniente debe de ser el más eficaz. Si no, nos expondríamos a un divorcio entre el país real y legal, que suele ser fatal, precisamente para el legal". Véase SARTORI, Giovanni y otros. "Consideraciones sobre alternativas semipresidenciales y parlamentarias de gobierno", en Estudios Públicos, No 42, 1991, p. 30

${ }^{18}$ Véase ACKERMAN, Bruce. We The People: Foundations. Cambridge, Harvard University Press, 1991. Es en esa época en que se registra la mayor participación electoral de la historia en Chile: en el plebiscito de 1988, votó el 96,6\% del padrón electoral; y en las elecciones presidenciales y parlamentarias de 1989, el 92,3\% del padrón electoral. Veáse NAVIA, Patricio. Las Grandes Alamedas: el Chile post Pinochet. Santiago, COPESA, 2004, p. 85. Navia, comparando la importancia política que para Chile tiene el golpe de Estado de 1973 y el plebiscito de octubre de 1988, sugiere que este último "es un momento fundacional que mira hacia el futuro" (Ibíd., p. 109; el énfasis es mío).
}

${ }^{19}$ WALDRON, Jeremy. The Dignity of Legislation. Cambridge, Cambridge University Press, 1999, p. 139. La traducción es mía. 


\section{La política del consenso y el nuevo papel del Poder Judicial}

$\mathrm{Al}$ abrazar esta forma de lidiar con el desacuerdo, las elites políticas fijaron el escenario para un período en que la participación de ciudadanos y ciudadanas fue paulatinamente postergada. A pesar de las reformas a la Constitución que han servido para vestirla de legitimidad, la percepción de que se vive en una democracia "tutelada", incompleta, poco democrática, no es difícil de hallar. Las expectativas puestas en las bondades del sistema democrático eran, finalmente, mayores que la disposición a proveer mecanismos de genuina intervención en los procesos de transformación social. Hacerse cargo del país en las sombras de la dictadura militar pareció ser una tarea demasiado pesada como para encargarse de las demandas por participar en los asuntos públicos. A fin de cuentas, tanto espacio público no había.

A causa de lo anterior, un nuevo escenario para la resolución de disputas políticas comenzó a aparecer: el Poder Judicial. Los militares, como se sabe, no intervinieron este Poder del Estado, el que, frente a las ramas políticas, ha sido tradicionalmente el menos determinante en delinear el interés público.20 Lo cierto es que tal intervención era innecesaria por cuanto el Poder Judicial se había opuesto explícitamente al gobierno de la Unidad Popular. Junto con ello, también es conocida la poca diligencia con la que la Justicia actuó, por regla general, durante los años de dictadura.21 Habiéndose recuperado la democracia en Chile, las agencias multilaterales veían la necesidad de implementar reformas judiciales como el paso siguiente para asegurar el estado de derecho, tanto en Chile como en los demás países de la región.22 A pesar de que la batalla más dura ya había sido vencida, era evidente que el sistema de administración de justicia, en general, requería una profunda revisión.23

Por otra parte, las demandas sociales se tornaban más complejas y más diversas. Las violaciones masivas y sistemáticas, si bien seguirían por mucho tiempo representando el paradigma del debate sobre derechos humanos, no serían las únicas exigencias de derechos civiles y libertades públicas que los ciudadanos presentarían. Indígenas, mujeres, personas con VIH-SIDA o con discapacidades, entre otros grupos, comenzaron a ver en la democracia el tiempo y modo para avanzar sus propias exigencias. Sin embargo, no había para ello canales políticos adecuados en los cuales canalizar estas deman-

\footnotetext{
${ }^{20}$ Es sintomático que en la Constitución de 1980, además de estar tratado después del Ejecutivo y del Legislativo, el nombre del capítulo donde se establece la regulación constitucional de la Justicia lleve como título "Poder Judicial", en circunstancias que el capítulo IV y V se titulan, respectivamente, "Gobierno" y "Congreso Nacional”, y no "Poder Ejecutivo" y "Poder Legislativo".
}

${ }^{21}$ Basta con citar el Informe de la Comisión sobre Prisión Política y Tortura, dado a conocer en noviembre de 2004, para hacer presente una de las omisiones voluntarias más vergonzosas de la Judicatura chilena. Allí se califica la actitud de la Corte Suprema -de no súper vigilar los tribunales militares en tiempo de guerra- como una verdadera "abdicación" de sus facultades constitucionales (p. 183), agregando que la Corte, junto con "ceder el terreno para la acción discrecional de las nuevas autoridades y sus agentes [...] hizo caso omiso de los abusos cometidos contra personas dejadas en total indefensión frente a aquellas arbitrariedades. Y esto, a pesar de que desde el inicio, éstas fueron denunciadas con insistencia por los abogados defensores [...]" (idem).

22 Véase MCCLYMONT, Mary y GOLUB, Stephen (eds.). Many Roads To Justice: The Law Related Work, of Ford Foundation Grantees Around the World. The Ford Foundation, 2000. Sobre la influencia de actores internacionales y transnacionales en el ámbito doméstico en Latinoamérica, véase KECK, Margaret E and SIKKINK, Kathryn. Activist Beyond Borders. Advocacy Networks in International Politics. Ithaca, Cornell University Press, 1998, pp. 79-120.

${ }^{23}$ La participación de la sociedad civil en los procesos de reforma judicial en América Latina es una muestra, para algunos, de una nueva relación entre los ciudadanos y las estructuras estatales. Véase AA.VV. Justicia y Sociedad Civil: El papel de la sociedad civil en las reformas a la justicia. Estudios de caso en Argentina, Chile, Colombia y Perú. Buenos Aires, CEJA/INECIP, 2003. 
das. Como dije más atrás, el regreso de la democracia no significó necesariamente un foro político más robusto donde presentar estas "nuevas" exigencias ciudadanas. 24

Al mismo tiempo, académicos y activistas lanzaban diversos proyectos enfocados no solo en asuntos institucionales del Poder Judicial -como la creación de Consejos de la Magistratura o Academias Judiciales-, sino también en esfuerzos sustantivos por promover cambio social a través de los tribunales de justicia. Muchos de ellos volvían encandilados con el progresismo de la Corte Warren de los Estados Unidos, que avanzó una notable jurisprudencia en materia de derechos civiles durante la mitad del siglo pasado, y que aún ilumina a numerosos constitucionalistas del Norte, no obstante el evidente cambio en las circunstancias actuales.

Con poco espacio para la participación política y un importante entusiasmo por crear cortes tipo Warren a lo largo de América Latina, activistas y académicos comenzaron a llevar demandas sociales o políticas al "foro de los principios", como diría Dworkin, en lugar de avanzar dichas demandas en los apasionados salones del Congreso. ¿Estaba el Poder Judicial chileno en condiciones de abordar semejante tarea? ¿Podía un Poder del Estado acostumbrado a una aproximación al derecho eminentemente formalista lidiar con demandas basadas en la protección de derechos fundamentales? Los jueces fueron, a mi parecer, abruptamente puestos en la (incómoda) posición de resolver problemas que los chilenos estábamos acostumbrados a llevar ante políticos, no expertos legales.

La cultura legal chilena, es sabido, ha estado fuertemente comprometida con el estudio del significado de los textos legales -el "sentido y alcance" de las normas-, tanto en la interpretación de derecho privado, como en la interpretación constitucional.25 Más aún, la forma de entender la interpretación de los textos de derecho civil, por ejemplo, pasó de manera más bien acrítica a gobernar las reglas de interpretación de los preceptos constitucionales. $\mathrm{O}$, para quienes descreen de la distinción entre derecho privado y derecho público, la interpretación de cuestiones relativas a la tutela de derechos constitucionales se ha hecho de manera análoga a la forma como se resuelven disputas en las que están involucrados derechos subjetivos privados. 26

La interpretación constitucional ha adoptado, a mi juicio, un modelo de derecho privado que enfatiza una lectura positivista y en extremo formal del texto constitucional. El contraste en esta parte con la construcción de significado constitucional, si hemos de seguir el sugerente análisis de Siegel, es elocuente: según ella, "en la tradición estadounidense, el texto [constitucional] importa en tanto representa el lugar donde se encuentran las interpretaciones y prácticas que autorizan, promueven y dan fuerza a los ciudadanos ordinarios para que avancen argumentos y entendimientos sobre el sentido de la Constitución”.27 Pareciera que en nuestra práctica constitucional, el texto importa más bien porque se le considera como un cuerpo legal, de alcance y posibilidades semejantes a las del Código Civil siguiendo con la comparación. De suerte que si de los ciudadanos no se espera que generen prácticas sociales que permitan dotar de significados alternativos al derecho privado, entonces lo mismo puede predicarse de la construcción de significado constitucional. Pareciera que no esperamos de éstos que

\footnotetext{
${ }^{24}$ Especialmente significativa ha sido la distancia entre los grupos indígenas y el Estado una vez recuperada la democracia. Analizo esta cuestión en CONTESSE SINGH, Jorge. "La rebelde democracia. Una mirada a la relación entre los mapuche y el Estado chileno", en SABA, R. (ed.). Los límites de la democracia. Buenos Aires, Editores del Puerto, 2005, pp. 239-258.

${ }^{25}$ Véase CORREA SUTIL, Jorge. "The Judiciary and the Political System in Chile: The Dilemma of Judicial Independence During the Transition to Democracy", en STOTZKY, Irwin (ed.). Transition to Democracy in Latin America: The Role of the Judiciary. Boulder, Westview Press, 1993, y SQUELLA, Agustín (ed.). La evolución de la cultura jurídica chilena. Santiago, CPU, 1994.

${ }^{26}$ CONTESSE, supra nota 11.

${ }^{27}$ SIEGEL, Reva B. "Text in contest: Gender and the Constitution from a Social Movement Perspective”, en U. Pa. L.

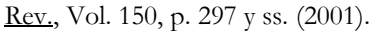


argumenten autoritativamente lo que la Constitución es (o debiera ser), no obstante ser ello consustancial a una práctica constitucional democrática.

Con todo, lo cierto es que actualmente la ciudadanía parece aceptar que el Poder Judicial sea un ámbito en que legítimamente se resuelvan constitucionalmente disputas sobre sus intereses sociales y valóricos. Una suerte de cultura del litigio constitucional en cuestiones sociales es cada vez más familiar, fenómeno que algunos denominan "judicialización de la política”28 - o "juridificación del conflicto político", si se trata de la solución que el derecho puede ofrecer al desacuerdo político.29 Otros sugieren una suerte de "vulgarización del derecho" por causa del incremento en el litigio constitucional, toda vez que la Constitución se utiliza de manera más expedita y, muchas veces, aseguran, con poca diligencia.30 No parece aventurado pensar que al encontrarse el foro político vedado a ciertos grupos y ciertas demandas, estos han encontrado en las cortes una vía para participar políticamente de la empresa común que es conducir los destinos de la nación.

Robert Post, otro destacado miembro del constitucionalismo popular, observa que ningún jurista con el cual él es familiar ha llegado tan lejos como para "caracterizar al sistema adversarial como una estructura de autogobierno democrático", incluso en el evento de estar frente a "un tribunal comprometido con la correcta interpretación de la ley y abogados que cumplan una función epistémica de asegurar que dicho tribunal considere cuidadosamente todas las pretensiones de las partes litigantes".31 Desde una perspectiva normativa lo anterior parece plausible. Con todo, y tal como he sugerido, algunos grupos sociales efectivamente ven el foro judicial como un mecanismo o canal en el cual desplegar los argumentos a favor de sus pretensiones. Desde esta óptica, la utilización del sistema judicial como una estructura de autogobierno democrático sí ha ocurrido $-\mathrm{y}$, debe notarse, seguirá acaeciendo.32 Al revisar el caso de la "píldora del después", en efecto, podremos decir algo con respecto a la tesis de Post. Este caso, situado en el contexto del litigio judicial sobre cuestiones relativas a políticas públicas, da cuenta de la manera distorsionada como la ciudadanía y los poderes públicos interactúan cuando se encuentran frente a una decisión constitucional que reclama la intervención de todos los (real y potencialmente) afectados. Veremos, por una parte, que existe una desconexión entre

${ }^{28} \mathrm{SABA}$, Roberto P. "Las decisiones constitucionales de Ulises. Acerca de las dificultades para la construcción colectiva de una práctica constitucional en Argentina", en SABA, R. (ed.) Los limites de la democracia. Buenos Aires, Editores del Puerto, 2005, pp. 279-304.

${ }_{29}$ ATRIA, Fernando. "El derecho y la contingencia de lo político", en Revista Derecho y Humanidades, No 11, 2005, (pp. 1939) p. 26.

${ }^{30}$ Véase CORREA, Rodrigo P. "Vulgarización por constitucionalización”, en Revista Derecho y Humanidades, No 11, 2005, pp. 161-175. En contra de la tesis de Correa, véase ALEGRE, Marcelo. "Vulgarización y deterioro del derecho democrático", en Revista Derecho y Humanidades, $\mathrm{N}^{\circ} 11,2005$, pp. 177-189. Otra causa del uso incremental de la herramienta de litigación es el entendimiento de que los derechos fundamentales no solo son oponibles ante el Estado, sino también ante particulares. Esta novedosa interpretación de la práctica constitucional chilena, sin embargo, no deriva de una sofisticada dogmática sobre el alcance de los derechos fundamentales (véase, supra, texto que acompaña a las notas 9 y 10). La existencia del "efecto horizontal" de los derechos constitucionales es, en verdad, una mala comprensión de la manera como las cortes debieran lidiar con tales asuntos. En otras palabras, dicha práctica, profusamente aceptada, no proviene de una compleja reflexión dogmática sobre sus implicaciones, como ha ocurrido, por ejemplo, en Alemania, Sudáfrica o, especialmente, Irlanda, sino justamente de la falta de discusión sobre ella.

${ }^{31}$ POST, Robert. "Democracy, Popular Sovereignty, and Judicial Review”, en Cal. L. Rev., 1998, Vol. 86, p. 429 y ss.

32 Un buen ejemplo de esto son las estrategias de participación que organizaciones ciudadanas y minorías desarrollan para avanzar sus agendas. Quizá el caso reciente más emblemático lo constituyan las minorías sexuales, quienes han mostrado, tanto en Chile como en otros países, una sofisticada capacidad de movilización, incluyendo, entre otros, el litigio judicial, el lobby parlamentario y manifestaciones culturales. Para una descripción de estos fenómenos en el caso estadounidense, véase ESKRIDGE, William N. Jr. Equality Practice: civil unions and the future of gay rights. New York, Routledge, 2002, y REED, Douglas S. "Popular Constitutionalism: Toward a Theory of State Constitutional Meanings", en Rutgers L. J., 1999, Vol. 30, pp. 871 y ss. 
los idiomas constitucionales que hablan unos y otros; y, por otra, notaré cómo la necesidad de los ciudadanos de intervenir en los procesos de transformación social -cuestión que ha sido puesta de manifiesto por algunos estudios-33 se expresa en el escenario de una disputa judicial sobre derechos fundamentales. Al observar lo anterior, no parecerá inapropiado preguntarse por las posibilidades y también los problemas de concebir la estructura judicial como una "estructura de autogobierno democrático". Se trata, como advirtiera Russell, de la forma como el poder pasa constantemente "de una forma a otra, siendo el deber de las ciencias sociales el desentrañar las leyes que gobiernan tales transformaciones".34 En este trabajo, junto con arrojar luz sobre el precario diálogo constitucional que es posible apreciar en la práctica legal chilena, se intenta comprender de modo complementario (aunque no exclusivo) la manera en que la necesidad y búsqueda por poder de grupos que quieren reconocerse constitucionalmente -e.g., las mujeres- debe acomodarse dentro las estructuras formales del derecho. Por ello, resulta fundamental para el análisis que ahora emprendo entender que los grupos que se identifican detrás de ciertas concepciones constitucionales -como, por ejemplo, el derecho a decidir si y cuándo embarazarse o el derecho de un pueblo indígena a desarrollar su cultura- en definitiva persiguen poder (que, a su turno, les permita influir en decisiones colectivas).

\section{La batalla judicial por una píldora en ausencia de diálogo constitucional}

En lo que sigue quisiera discutir desde una perspectiva no dogmática el caso de la llamada "píldora del día después". 35 Mi interés es presentar este caso como una muestra paradigmática de (la falta de) diálogo entre los poderes del Estado, en particular, entre los poderes políticos y los tribunales de justicia. Específicamente, me interesa analizar el modo disimulado por el cual se argumenta constitucionalmente en Chile. Para ello, consideraré los argumentos que tanto el Ejecutivo como el Poder Judicial han desplegado alrededor de este caso -el Congreso Nacional, cabe señalar, no ha argumentado (aún).36 Además, procuraré referir el modo en que los ciudadanos han abordado este caso toda vez que ello también contribuye a advertir la precariedad del debate constitucional en Chile. El caso, pienso, puede ser explicado como un caso de "jurisprudencia desde abajo" 37 , por lo que sería posible reconstruirlo como un escenario de constitucionalismo popular, esto es, una situación en la que el entendimiento constitucional de uno o más grupos sociales debiera ser determinante para el modo en que las autoridades -administrativas, judiciales y legislativas- sancionan y dirimen legalmente el desacuerdo político.

Los proyectos de ley sobre la materia que actualmente se encuentran en el Congreso contienen valiosa información sobre el desarrollo de las políticas sobre derechos sexuales y reproductivos en

\footnotetext{
${ }^{33}$ De acuerdo con el Programa de Desarrollo de las Naciones Unidas en Chile, ante la mejora general en las condiciones de vida actuales, la sociedad chilena desea, entre otras cosas, mayores espacios en los cuales poder influir en la conducción y el desarrollo del país. Véase PNUD. El poder: ¿̇para qué y para quién?. Informe de Desarrollo Humano 2004.

${ }^{34}$ RUSSELL, Bertrand. Power. New Cork, Routledge, 1996 (1938), p. 5.

${ }^{35}$ Para un análisis de dogmática jurídica sobre este caso, véase BASCUÑÁN RODRÍGUEZ, Antonio. "La píldora ante la jurisprudencia", en Estudios Públicos, No 95, Santiago, invierno, 2004, pp. 43-89, y FERMANDOIS, Arturo. "La píldora del día después: aspectos normativos", en Estudios Públicos, No 95, Santiago, invierno, 2004, pp. 91-118.
}

${ }^{36}$ El Congreso Nacional ha sido un actor sintomáticamente pasivo en esta discusión constitucional. Los únicos esfuerzos legislativos por promover cuerpos legales comprensivos en materia de derechos sexuales y reproductivos se reducen a un proyecto de ley presentado en 2000 por algunos diputados (Boletín No 2608-11, en trámite) y el proyecto de reforma constitucional que establece el derecho a ejercer la libertad sexual y reproductiva, elaborado al calor de la batalla judicial por la píldora, en octubre de 2004 (Boletín No 3702-07, en trámite).

${ }^{37}$ Véase MCCANN, Michael W. Rights at Work, Chicago, University of Chicago Press, 1994, pp. 21-22. 
relación con la forma en que la sociedad chilena ha caminado hacia una sexualidad más abierta y hacia la necesidad de disponer de métodos de planificación familiar. Hay allí, en realidad, una opinión sobre la respuesta constitucional y legal que un cierto entendimiento de la facticidad demanda. Y, como opinión que es, reclama argumentos a favor y en contra que, al menos en el foro legislativo, aún no se producen: ambos proyectos prácticamente no han avanzado en su tramitación -el proyecto general está inmóvil desde fines de 2000 y el de reforma constitucional tampoco ha pasado valla alguna.

Con todo, el proyecto que busca enmendar la Constitución, como consecuencia que es de la serie de decisiones judiciales emitidas con ocasión del caso de la "píldora del día después" -en especial, la sentencia de la Corte Suprema de agosto de 2001 que prohibió parcialmente su comercialización-,38 recoge explícitamente aspectos de la discusión cultural que existe sobre la procedencia de este método de planificación familiar. La propuesta, en efecto, acusa que

"A pesar de toda la evidencia científica existente, la utilización de este fármaco ha sido resistido por ciertos sectores conservadores de la sociedad chilena quienes han recurrido a los tribunales de justicia para impedir su comercialización y utilización. Lamentablemente nuestros tribunales sin entrar a un procedimiento sumarísimo, extraordinario y de carácter cautelar como lo es el recurso de protección (sic), han fallado por votación dividida en contra de lo resuelto por la autoridad sanitaria, pasando por alto la discusión científica sobre la materia y sobre todo pasando por sobre la opinión, libertad y autodeterminación de los sujetos a quienes alcanzan los efectos del veredicto judicial: las mujeres chilenas en edad fértil".39

Este solo párrafo de la moción da lugar a importantes preguntas. ¿Hace falta introducir, antes que todo, un nuevo numeral $2^{\circ}$ al artículo 19 de la Constitución, desordenando la obra de los comisionados de los setenta, rejuvenecida por los homogéneos constituyentes del 2005, para asegurar "el derecho a la libertad sexual y reproductiva"? ¿Cuál es la relevancia de la "votación dividida" en la Corte a la que se alude? ¿Hasta dónde debe el Congreso comentar el grado en que el Poder Judicial escruta las actuaciones de la autoridad administrativa? ¿Cuál es la relevancia de la evidencia científica? Todas estas interrogantes no pueden ser respondidas, naturalmente, en un trabajo que aspira a ser breve; a todas ellas, sin embargo, subyace la cuestión que motiva estas líneas. El Congreso deberá hacerse cargo de decisiones judiciales que algunos de sus miembros estiman "desafortunadas". ¿Cómo se inscribe esta circunstancia en un análisis sobre el diálogo constitucional entre actores estatales y entre éstos y los demás actores sociales que contribuyen a dotar de significado a la práctica constitucional? Una mirada a los dos procesos judiciales que la "píldora del día después" ha generado en los últimos años mostrará, al menos parcialmente, la oscuridad con la que se debate constitucionalmente en Chile.

\section{El primer caso}

En 2001, el Instituto de Salud Pública de Chile (ISP) autorizó a un laboratorio particular a importar y comercializar la droga levornogestrel, conocida como "píldora del día después". Pocas semanas después del anuncio, organizaciones autodenominadas como "pro-vida" recurrieron de protección en contra de la autorización que la Administración otorgara, solicitando a la Corte de Apelaciones de Santiago que declarara que el acto por el cual se autorizaba la importación y distribución comercial de la droga era ilegal y arbitrario y que atentaba en contra del derecho a la vida de los no nacidos. Los

\footnotetext{
${ }^{38}$ Corte Suprema, sentencia de 31 de agosto de 2001, Rol No 2186-2001.

${ }^{39}$ Boletín No 3702-07, p. 2. Como se sabe, y a diferencia de lo que dice el proyecto de ley, los tribunales de justicia precisamente entraron en un procedimiento sumarísimo y cautelar, como es el recurso de protección.
} 
recurrentes sostenían que la píldora era abortiva y, siendo el aborto un delito sancionado por la legislación criminal, la autorización era inconstitucional.

La Corte de Santiago declaró, habiendo conocido el fondo del asunto, que el recurso era inadmisible por cuanto había sido deducido a favor de una clase de seres no identificados ni identificables, como son los no nacidos de Chile.40 Y, no siendo esta acción constitucional una que pueda interponerse como acción colectiva, en beneficio de una clase de personas no individualizadas, los recurrentes, sostuvo la Corte, carecían de legitimación activa. El recurso, en consecuencia, debía rechazarse sin necesidad de determinar acaso la autorización dada por el ISP era ajustada o no a derecho, y sin perjuicio del debate sustantivo que "la píldora" había originado en la comunidad. Sin duda una hábil salida para no hacerse cargo de un intenso debate social que, al menos según lo entendían algunos, requería de sanción jurídica.

La decisión provocó un intenso debate entre organizaciones ciudadanas, la Iglesia católica, la Administración, algunas congresistas, médicos y juristas. En este escenario, la Corte Suprema específicamente su Tercera Sala Constitucional- revocó el fallo en un estrecho pronunciamiento que, a mi parecer, constituye una de las decisiones más enigmáticas pronunciadas por la justicia constitucional chilena. Desde el punto de vista formal, la Corte sostuvo, por una parte, que los no nacidos de Chile no son una clase de individuos no identificados y, por otra parte, que aceptar la legitimación activa de las organizaciones "pro-vida" no importa que el recurso de protección sea considerado una acción colectiva o de carácter popular. Y, en cuanto al fondo, la Corte Suprema, sabemos, determinó que la vida humana comienza con la concepción. Como la píldora produce sus efectos una vez que la concepción ha ocurrido, razonaron los ministros en el voto de mayoría, ella interrumpe el desarrollo de una vida humana en gestación y, por lo tanto, debe considerarse como abortiva. En consecuencia, la autorización que el ISP diera para su importación y venta era un acto inconstitucional -o, en la jerga de protección, un acto arbitrario e ilegal que vulneraba el derecho a la vida de los no nacidos. La importación, distribución y venta de la droga debía parar.41

El voto de mayoría de la Tercera Sala de la Corte Suprema, como se ve, estableció en un proceso de urgencia, sin rendición de pruebas al modo de un juicio de lato conocimiento, nada menos que jel comienzo de la vida humana! $\mathrm{Ni}$ aun la ciencia médica ha arribado a una conclusión unívoca a este respecto - menos aún, otros tribunales a los que les ha tocado abordar casos de aborto. Pero la Corte Suprema chilena fue capaz de zanjar el asunto prescindiendo incluso de fundadas opiniones técnicas en sentido opuesto a su decisión.42

Las expectativas sociales en lo que las Cortes harían eran altas: el asunto se debatía a lo largo del país en variados foros y, naturalmente, muchos ojos estaban puestos en la forma como se resolvería jurídicamente una cuestión con numerosas aristas no legales. Hubo quienes insistían en la necesidad de dar una salida "política" -como opuesta a la solución jurídica que podía ofrecer el Poder Judicial. La Corte Suprema, impávida, más bien acalló las múltiples voces que reclamaban un espacio de intervención en esta contienda, llamémosla así, meta-judicial. Reva Siegel, militante de la corriente del constitucionalismo popular en Estados Unidos, observa que "el Tribunal Supremo [de dicho país] normalmente interpreta la Constitución en medio de diversas opiniones en competencia acerca de su significado, y no ejerce o no puede ejercer su autoridad silenciando entendimientos e interpretaciones alter-

${ }^{40}$ Corte de Apelaciones de Santiago, sentencia de 28 de mayo de 2001, rol No 580-2001.

${ }^{41}$ Corte Suprema, sentencia de 31 de agosto de 2001, Rol No 2186-2001.

${ }^{42} \mathrm{La}$ Corte, por ejemplo, contaba con la información de que a comienzos de la década de los noventa, la píldora de anticoncepción de emergencia había sido prohibida. Sin embargo, la evidencia científica producida con posterioridad a la fecha de prohibición -1990-, acompañada al proceso, generaba al menos dudas con respecto a dicha conclusión. 
nativas de dicho significado".43 Esto es válido también para Chile. No obstante haber una tradición de construcción de sentido constitucional por parte de la ciudadanía distinta entre los dos países, la creciente litigación de asuntos sociales (o "políticos") ha producido, entre otras cosas, una mayor sensibilidad hacia el lenguaje constitucional. Con todo, lo que nuestra Corte Suprema hizo, en el caso de la "píldora del día después", fue precisamente precluir el debate que se desarrollaba entre actores sociales, como organizaciones de mujeres, grupos "pro-vida", la Iglesia católica, algunas parlamentarias, jueces y académicos.

En vez de actuar como una Corte "minimalista", en el sentido de Sunstein44, la Corte Suprema chilena pronunció una decisión de fondo sustantivamente profunda y genérica que debilita la integridad de la práctica constitucional, pues desconoce las numerosas, intensas y contradictorias opiniones que sobre la materia tienen derecho a existir. No es fácil para un tribunal de justicia lidiar con un asunto de esta naturaleza, sin duda. Pero ante la dificultad, ¿no debiéramos acaso esperar una actitud más cauta de parte de él, en vez de un fallo que aspira a resolverlo todo? La Corte decidió demasiadas cuestiones sin tener que hacerlo; $y$, además, lo hizo en contradicción con sus pronunciamientos previos. 45

La droga, sin embargo, no fue en definitiva erradicada. A pesar del pronunciamiento de la Corte, todavía era posible conseguirla. Y es que justo antes de que la Corte Suprema revocara el fallo de primera instancia, el ISP dio autorización a otro laboratorio para que comercializara la píldora, esta vez bajo una marca distinta, aunque de idéntico componente químico. Los recurrentes que habían obtenido una decisión favorable solicitaron que ésta se hiciera extensiva a cualesquier otro medicamento que produjese los mismos efectos de aquel cuya venta se había declarado inconstitucional. El argumento, simple y claro, sostenía que era el efecto abortivo lo que debía prohibirse, no la compañía A o B que lo distribuyera. Así, era el Ejecutivo el que hacía ahora una inteligente jugada: sin desconocer el fallo que le reprochaba su actuar, por medio de esta nueva autorización en los hechos sí lo rechazaba. $\mathrm{Al}$ otorgar este nuevo permiso, la Administración no hacía más que argumentar de manera oculta en términos constitucionales: ni una sola palabra sobre el derecho de las mujeres a decidir sobre su sexualidad; ni una palabra sobre los derechos en colisión de los no nacidos. Para el Ejecutivo, éste era un asunto de meras formalidades legales. ¿Se prestaría el Poder Judicial para esta movida?

La Corte Suprema, en vez de zanjar esta pregunta fundamental, reenvió el asunto a la Corte de Apelaciones de Santiago para que ésta lo hiciera. La Corte capitalina sorpresivamente dijo que la sentencia de la Suprema que revocaba su fallo no alcanzaba al segundo acto administrativo por el que se daba una nueva autorización para que la píldora fuera comercializada. El argumento principal era que el segundo laboratorio al que se le había permitido vender la droga no era parte del litigio judicial que había terminado en la Suprema, por lo cual, de acuerdo con la retórica del artículo $3^{\circ}$, inciso $2^{\circ}$, del

\footnotetext{
${ }^{43}$ SIEGEL, supra nota 27, p. 350.

${ }^{44}$ SUNSTEIN, Cass R. One Case at a Time. Cambridge, Harvard University Press, 1999. Sunstein afirma que los jueces 'minimalistas' tratan de evitar "la adopción de reglas vagas y teorías abstractas, y asimismo intentan concentrar su atención solamente en aquello que resulta necesario para resolver disputas particulares", alejándose de una concepción 'maximalista' del ejercicio judicial. Sunstein advierte que la noción de "maximalismo' "está lejos de ser perfecta, por cuanto nadie busca decidir, en cada caso, todo lo que pudiese ser decidido. El término debiéramos entenderlo", dice, "como una mera referencia para aquellos que buscan decidir casos de un modo que fije reglas abiertas para el futuro y, al mismo tiempo, dotar de poderosas justificaciones teóricas a estas decisiones" (Ibid., pp. 8-9).
}

${ }^{45}$ La Corte Suprema había sostenido, de manera clara y bastante uniforme, que el recurso de protección no podía ser deducido a nombre de una clase o grupo de individuos no identificados (o identificables). Véase Revista Gaceta Jurídica, No 139, 1992 , p. 66 y Revista Fallos del Mes, No 309, 1984, p. 393. Al observar este hecho, no sugiero que la Corte no pueda ir en contra de sus decisiones anteriores -en verdad, bueno sería que la Corte de hecho fuera en contra de varias de sus doctrinas. Lo que quiero remarcar aquí es que la Corte Suprema, al aceptar la posibilidad de recurrir a favor de todos los no nacidos, en los hechos revierte esta doctrina, aun cuando insista en que, ejercida de esta manera, no se trata de una acción popular o de clase. 
Código Civil -que dispone que las sentencias judiciales solo tienen fuerza obligatoria respecto de la partes y causas en que actualmente se pronuncien-, no era posible hacer extensivo el fallo a quien no había intervenido en el pleito. La Corte Suprema confirmó el parecer de la Corte de Apelaciones y, de este modo, se llegaba al absurdo de tener una droga considerada abortiva que, sin embargo, podía ser comercializada en un país en el que cualquier tipo de aborto es constitutivo de delito.

El Congreso Nacional era, en este cuadro, más bien espectador. El proyecto mencionado más atrás no se encontraba aún en la agenda legislativa y solo un reducido número de parlamentarias y parlamentarios participaron del debate público originado con estas decisiones judiciales. Hubo diputadas que se unieron a las protestas de organizaciones de la sociedad civil, pero no alcanzó a haber un intento deliberado de intervenir como actor político en la discusión. De esta manera, el escenario en que una disputa constitucional sobre los límites y alcances del derecho a la vida frente a los reclamos por autonomía sexual y reproductiva de parte de las mujeres no pudo darse. Los poderes del Estado actores institucionales de este debate- hablaron, cada uno, su propio lenguaje. No obstante la evidente posibilidad (y aun deber) de referirse a la cuestión en clave de derechos subjetivos públicos, el Ejecutivo hizo como que no había fondo en este asunto, lo que fue tomado por los tribunales (aunque llevado a otro lugar), mientras el Congreso sí plasmó las implicaciones de las diversas soluciones legales al tema, conformándose con la presentación de un proyecto de ley. Frente a ello, la disputa de universos normativos que bajo la Constitución levantaran los grupos a favor y en contra de la píldora debió circunscribirse a algunos intercambios en la prensa y otras tantas discusiones académicas.

\section{El segundo caso}

Las organizaciones "pro-vida" naturalmente no se quedaron tranquilas. Tras la decisión, presentaron una nueva acción judicial para impedir que la anticoncepción de emergencia pudiese ser libremente distribuida. Esta vez se trató de una demanda de nulidad de derecho público, ante un tribunal de letras. El argumento principal era de sentido común: la Corte Suprema de Chile había declarado que la droga levonorgestrel tenía efectos abortivos, por lo cual, al autorizar a un laboratorio diferente para que la comercializara bajo un nombre distinto, la Administración actuaba al margen de la Constitución. El acto administrativo por el cual se había otorgado el permiso debía declararse nulo de derecho público.

La principal diferencia entre este caso y el anterior es que ahora las partes intervinientes tenían amplio margen para acreditar sus pretensiones (no así en un juicio sumarísimo, como es el recurso de protección). Grupos de mujeres quisieron entrar en la discusión judicial para así dar tribuna a sus voces y, contra la opinión de Post, utilizar a los tribunales como una "estructura de autogobierno democrático".46 El tribunal civil rechazó su petición pero la Corte de Apelaciones ordenó que se admitiera la intervención de uno de estos grupos -no así, de otras mujeres que reclamaban participar del debate- lesionando la legitimidad de la deliberación. De esta forma, el Poder Judicial llevaba adelante una nueva discusión sobre este espinudo tema; con una representación menor de las partes actualmente interesadas, forzada por la ciudadanía y puesta en clave de derechos fundamentales a pesar de la resistencia estatal.

Algunas semanas después del anuncio del Ministerio de Salud que distribuiría de manera gratuita la píldora a las víctimas de violación -una medida vigorosamente resistida por la Iglesia católica, sectores de la derecha política y algunas organizaciones ciudadanas- el tribunal civil acogió la demanda interpuesta.47 La autorización otorgada por el ISP era declarada nula (de derecho público) y, conse-

\footnotetext{
${ }^{46}$ Véase texto que acompaña a la nota 31.

$4720^{\circ}$ Juzgado Civil de Santiago, Centro Juvenil Ages v. Instituto de Salud Pública, Rol No 5839-02.
} 
cuentemente, la venta y distribución debía prohibirse. A diferencia del dictamen tipo "todo-loresuelvo" de la Corte Suprema, la jueza civil señalaba que no tomaría ninguna posición en el debate moral y religioso que se desarrollaba en Chile a causa de la "píldora del día después", pero que, al examinar la evidencia no conclusiva, ella le daría mayor peso relativo a la protección de los no nacidos (por considerarla "más conforme con la verdad"). No exagero al señalar que éste es el único argumento de la decisión. El resto de la sentencia se limita, como es normal en nuestra práctica judicial, a reiterar los argumentos de las partes, sin ofrecer una respuesta oportuna a ellos. No es que la jueza debiera responder, 'maximalistamente', todas las preguntas que surgen con este caso. Pero en su despacho se disputaban entendimientos y la más correcta interpretación constitucional sobre una sensible materia. Ella, sin embargo, nada sugirió. Nada dijo sobre aquellos sentidos y enfrentados entendimientos de la Constitución. Tanto la Administración como los grupos de mujeres apelaron la sentencia.

A pesar de los argumentos de las organizaciones de la sociedad civil, las presentaciones que sostenían las pretensiones de apelantes y apelados se basaban en cualquier elemento, excepto los derechos sexuales y reproductivos de las mujeres. La discusión, en efecto, giraba en torno a una cuestión fáctica, altamente debatida: el momento en que la vida humana comienza.48 Solo una vez que se determinara este hecho esencial, la Corte analizaría el mérito de la política pública de la Administración. Mientras el debate público se llenaba de editoriales, columnas de opinión, foros y discusiones sobre los derechos en colisión -los de las mujeres y los de los no nacidos-, el lenguaje que los abogados litigantes ofrecían a la Corte carecía de este componente constitucional, a mi juicio, gravitante.

El temor a una nueva decisión judicial que sofocara el debate público en cuestiones de moral, religiosidad y desacuerdo político cundía entre algunos. Sin embargo, contra las expectativas de muchos, la Corte de Apelaciones de Santiago, conociendo esta vez como tribunal de alzada en la demanda de nulidad de derecho público y no como primera instancia de un recurso de protección, desatendió la decisión de la Corte Suprema y reafirmó, en diciembre de 2004, que los demandantes carecían de la habilitación legal para reclamar judicialmente a favor de los no nacidos de Chile.49 Pero esta vez los ministros de la Corte capitalina fueron más allá de su tímido pronunciamiento de 2001 y entraron en la discusión pública. Siendo un asunto técnico no resuelto, tanto desde una perspectiva médica como moral, los jueces, sostuvieron, no pueden intervenir zanjando la discusión. De acuerdo al fallo,

"Sabido es que el derecho constituye un instrumento limitado, que solo puede solucionar determinados conflictos de la vida humana y no tiene ni puede tener la pretensión de resolver todas aquellas disputas que se presentan, sea, por ejemplo, en los ámbitos de la filosofía o de la ciencia y, ciertamente, desde luego, mucho menos aquéllos (sic) de significación religiosa".50

La deferencia sustantiva del Poder Judicial hacia las ramas políticas del Estado y la reticencia a suscribir alguna posición comprehensiva sobre el problema es la primera (notable) doctrina de este

\footnotetext{
${ }^{48}$ Que ésta sea una cuestión fáctica no quiere decir que sobre ella no existan posiciones, digamos, normativas o morales que intentan responderla. Aquí nada más sugiero que la primera palabra sobre el comienzo de la vida humana no la tiene -no puede tenerla-, para resolver esta controversia constitucional, el derecho, ni la moral, ni la filosofía, sino la ciencia. Y, consecuentemente, si la ciencia no provee de una respuesta unívoca, el derecho debe reconocer su incapacidad para dirimir la disputa y, antes que inundar los mundos normativos con sus reglas, retroceder y mediar el desacuerdo permitiéndolo, no suprimiéndolo.
}

${ }^{49}$ La Corte de Apelaciones también consignó que (a) la demanda no podía considerarse como una demanda colectiva, según lo sostenían los apelantes; (b) que la revisión judicial solo podía realizarse sobre controversias actuales, y no como un examen abstracto de constitucionalidad, y (c) que para cumplir con el mandato constitucional de proteger la vida del que está por nacer no puede haber incertidumbre acerca de la existencia de una vida humana. En tanto la evidencia médica y científica no es conclusiva, sostuvo la Corte de Apelaciones, no existe tal certeza.

${ }^{50}$ Considerando $16^{\circ}$. 
fallo.51 La ciudadanía estaba acostumbrada a ver cómo Cortes “jurispáticas”, pronunciaban fallos en los cuales los debates filosóficos, morales o religiosos, antes que comenzar, quedaban zanjados.52 Esta sentencia, sin embargo, parece ser una notable excepción. Aún más, tras el anuncio de la revocación del fallo de primera instancia, uno de los ministros de la Corte de Apelaciones declaró a la prensa que las objeciones morales, religiosas o filosóficas sobre la píldora debían ser resueltas por la sociedad, y no por ellos, los jueces. 53

Una vez más, era el turno de la Corte Suprema. Como la consistencia no es un elemento que pueda predicarse de los tribunales chilenos, en especial de la Corte Suprema, no parecía aventurado esperar una decisión distinta a la de 2001. Pero ¿sería posible que la misma Tercera Sala, comandada esta vez por uno de los jueces más conservadores del Poder Judicial chileno, permitiera la liberalización de una droga que ella misma había dicho producía efectos abortivos? No solo fue ello posible. La Corte pronunció un fallo unánime por el cual rechazó los recursos presentados por el grupo "pro vida", permitiendo la comercialización de la "píldora del día después". Nada más lejos que la idea de precedente en el trabajo de la Corte Suprema, no obstante ella se hizo cargo de la contradicción entre su decisión de 2001 y ésta, dada a conocer a fines de 2005. Según la Corte, desde que la primera sentencia tuvo su origen en un procedimiento de protección, la decisión allí alcanzada fue "sin perjuicio" de lo que se pudiera determinar en un procedimiento de lato conocimiento, como es, precisamente, la nulidad de derecho público. En esta interpretación, que responde al concepto de "cosa juzgada formal", la jurisprudencia de la Corte sí es consistente: ella entiende que las sentencias dictadas en sede de protección son de tutela, de emergencia, por lo que eventualmente pueden variar decisivamente. Eso fue, sin duda, lo que aquí aconteció. Pero, cabe preguntarse, si es cierto que la Corte es consciente de lo modificables que son las sentencias dictadas en sede de protección, ¿cómo se explica, entonces, el profundo fallo de 2001, donde dictaminó nada menos que el comienzo de la vida humana, frente al lenguaje cauto con el que debiera pronunciarse una sentencia que no pretende autoridad de cosa juzgada (material)? Si es cierto que un fallo de protección es débil frente a la contundente evidencia que debe pesarse en un juicio de lato conocimiento, la sentencia de 2001 se anota otra crítica más.

Pero en 2005, ya lo he dicho, la Tercera Sala de la Corte Suprema rechazó los argumentos de los recurrentes "pro vida" (iy en forma unánime!). Ahora bien, esto no significa, como podría pensarse, que la Corte desdijera de modo sustantivo su dictamen sobre el comienzo de la vida humana: para rechazar los recursos de casación presentados, la Tercera Sala argumentó básicamente sobre la falta de pruebas aportadas por el recurrente. A diferencia del fallo de 2001, esta vez su pronunciamiento es más complejo, sin duda, aunque ello no implica el que se haya hecho cargo del problema de entendimientos alternativos sobre los derechos constitucionales que esta vez se debatían en sede de casación. La Corte Suprema, a pesar de sostener que la Corte de Apelaciones cometió "un error de derecho" al rechazar la legitimación activa de los recurrentes, sostuvo que tanto la casación en el forma como en el

${ }^{51}$ En otro lugar he analizado cómo el Poder Judicial ha adherido explícitamente a doctrinas morales o religiosas comprehensivas, como la existencia de Jesucristo, proscribiendo, por dicha circunstancia, cierto arte considerado atentatorio en contra de dichas doctrinas y rehusando argumentar sobre la base de un uso público de la razón. Véase CONTESSE SINGH, Jorge. "Liberalismo político y posibilidades de la razón pública en Chile", en John Rawls: Estudios en su homenaje, Revista de Ciencias Sociales, No 47, Universidad de Valparaíso, 2002, pp. 679-701.

52 Uso el término "jurispático", que tomo del trabajo de Robert Cover, "Nomos and Narrative", en el sentido de que las cortes chilenas han usualmente interpretado la Constitución "en las sombras de la coerción”, suprimiendo o aun aniquilando sentidos e interpretaciones alternativas de la ley (o la Constitución). COVER, Robert M. "The Supreme Court, 1982 Term -- Foreword: Nomos and Narrative”, en Harv. L. Rev., 1983, Vol. 97, (pp. 4 y ss.), p. 40. La conexión entre este tipo de cortes y el maximalismo à la Sunstein es evidente: una corte maximalista lo que hace, entre otras cosas, es impedir el desarrollo de entendimientos alternativos sobre la ley, mediante decisiones que lo resuelven todo, con amplias doctrinas y profundas consecuencias.

${ }^{53}$ Ministro Hugo Dolmestch, 10 de diciembre de 2004, en

$<$ http://www.elmostrador.cl/modulos/noticias/constructor/detalle_noticia.asp?id_noticia=149801 $>$. 
fondo eran improcedentes.54 El voto disidente de 2001 terminaba señalando que el caso de la "píldora del día después" implicaba una discusión de fondo y obligaba "a adoptar una posición sobre el estatuto jurídico del embrión humano" 55 , cuestión que no podía responderse por medio de una acción cautelar, como es el recurso de protección. Este era, precisamente, el aspecto de fondo más determinante que se esperaba: ahora que efectivamente se había desarrollado un juicio de lato conocimiento, ahora que se habían analizado "informes científicos complejos y otras probanzas pertinentes" 56 , la Corte, al fin, podría determinar cuál era, en el derecho chileno, el estatuto jurídico del embrión humano. Tal cosa, sin embargo, no ocurrió. La Corte Suprema rechazó los recursos de casación en la forma y en el fondo inaugurando, sin decirlo, una nueva doctrina formal sobre habilitación legal para demandar "el derecho a vivir bajo el imperio de la ley", y dejando la pregunta sobre el fondo sin resolver. Tras su pronunciamiento, no sabemos mejor que antes cuál es el estatuto jurídico del embrión, ya que el recurrente, dijo la Corte, falló en acreditar un elemento esencial de su pretensión, a saber, que la píldora es abortiva. Así, la sentencia decretó que "no [fue] cuestión demostrada en este juicio la cualidad abortiva del fármaco aludido ni tampoco que su utilización pudiera provocar, en grado de certeza, un peligro de la vida del que está por nacer” 57 , razón por la cual el pronunciamiento de los jueces de fondo impugnado por la asociación "pro vida" era ajustado a derecho.

Es interesante la sentencia de la Corte Suprema. Por una parte, y de nuevo sin decirlo, parece (intentar) salvar el enorme fallo de 2001 sobre el origen de la vida humana al señalar que las pruebas aportadas en 2005 no dan cuenta, "en grado de certeza", de los riesgos de la droga para la vida del que está por nacer. Como se sabe, el recurso de protección admite ser interpuesto incluso cuando un derecho fundamental es amenazado; puede no haber certeza de que se va a perturbar o privar tal derecho, basta con que solo exista la apariencia de buen derecho -aquello que la jerga procesal denomina "fumus boni juris"- y aun así puede uno recurrir. Y, por otra parte, como consecuencia de este aserto, la Corte sugiere que, en el evento de que la ciencia médica adopte un acuerdo sobre la disputa acerca del comienzo de la vida humana, ella podría llegar al grado de certeza necesario para acoger la protección impetrada. En esta reconstrucción de la sentencia, hay que decir que la Corte sí retrocede y cede el paso a espacios no legales para dirimir la controversia. Pareciera que dependiendo del estado de la ciencia médica, las interpretaciones sobre derechos constitucionales van a ir en uno u otro sentido. Pero, a diferencia de la Corte de Apelaciones, no hay en el fallo del más alto tribunal un intento por mediar el conflicto social que supone la divergencia de opiniones, no solo científicas, sino también

\footnotetext{
${ }^{54}$ La manera como la Corte fundamenta la amplia habilitación legal para iniciar una demanda de nulidad de derecho público es notable. Si este trabajo buscara explicar dogmáticamente los alcances de la sentencia aludida habría mucho que decir. Valga anotar que la Corte señala, en el considerando $21^{\circ}$ de su fallo, que la legitimación activa del recurrente "se encuentra fundamentada en lo que dispone la Constitución Política de la República, en su artículo $19 \mathrm{~N}^{\circ} 1$ [...] en la norma del artículo $19 \mathrm{~N}^{\circ} 3$ inciso $1^{\circ}$ de la misma Carta Fundamental, y a mayor abundamiento dentro del amplio concepto del derecho de petición que se asegura de manera tan amplia en el $\mathrm{N}^{\circ} 14$ del mismo artículo 19...". Esta batería de derechos constitucionales -la protección de la vida, la igualdad en el ejercicio de los derechos y el derecho de petición-, radicados en un "cuerpo intermedio con personalidad jurídica, que propende a la defensa, protección, cuidado, preservación y desarrollo del pleno derecho a la vida desde el momento mismo de la concepción", es lo que habilita al recurrente, en concepto de la Corte, a solicitar tutela judicial a favor de una clase de seres no identificados, como son, los no nacidos. Será, sin duda, interesante ver cómo se desarrolla la práctica judicial después de la aceptación expresa por parte de la Corte Suprema del "poder del actor para acceder a la justicia, cuando se trate de la afectación de sus derechos o para demandar, como lo sostiene Fiamma, "el derecho a vivir bajo el imperio de la ley" (id., referencia bibliográfica omitida). Si la Corte hoy acepta que se pueda demandar en nombre del "derecho a vivir bajo el imperio de la ley", entonces ella ha modificado su jurisprudencia (véase, infra, nota 45).

${ }_{55}$ Corte Suprema, sentencia de 31 de agosto de 2001, Rol No 2186-2001, voto disidente, considerando $4^{\circ}$ (redacción del ministro Domingo Yurac).

${ }^{56}$ Id. cons. $3^{\circ}$.

${ }^{57}$ Corte Suprema, sentencia de 28 de noviembre de 2005, Rol No 1039-2005, considerando $34^{\circ}$.
} 
religiosas y morales, sobre los efectos e implicaciones de un método de planificación familiar. En otras palabras, a pesar de abandonar el desatado 'maximalismo' que caracteriza a la sentencia de 2001, la Corte (para estos efectos, el derecho) de todos modos no se refirió a los entendimientos producidos por comunidades normativas, como las mujeres y los representantes de los que están por nacer. Sobre esto corresponde hablar ahora.

\section{A modo de conclusión: dos escenarios diferentes; dos problemas (no tan) distintos}

Cuando la construcción de sentido o significado constitucional está en juego -en particular, aquella que versa sobre derechos fundamentales-, cabe preguntarse por la interrelación entre los diversos actores involucrados, tanto institucionales -e.g., el Ejecutivo y los tribunales de justicia- como no institucionales -por ejemplo, las organizaciones de la sociedad civil. ¿Qué podemos decir acerca del diálogo (o la falta de él) que tiene lugar entre diversas interpretaciones en competencia sobre el alcance y las posibilidades de la Constitución. Al abordar estas preguntas, la política del consenso que ha gobernado el espacio público, sumado al maximalismo judicial ejercido por una Corte Suprema con aversión a atender entendimientos sociales de un grupo de la población, constituyen notas salientes. Veamos cómo y porqué.

Al comienzo de este trabajo, describí brevemente el debate constitucional que existe desde algunos años en Estados Unidos y que cuestiona la posición de la Corte Suprema como el único o mejor intérprete de la Constitución Federal. En seguida, presenté el caso chileno como un escenario diferente y, consecuentemente, una situación también diversa. Me centré en el mecanismo político por el cual se hace política a través de prácticas de consenso deliberado - casi forzado. He sostenido que dicho mecanismo, sumado a un diseño institucional que distorsiona el sistema de representación política, fomenta la ausencia de diálogo constitucional entre actores estatales. Y, también he dicho, promueve un modelo de argumentación constitucional disimulada. La actual batalla judicial por la "píldora del día después" es una buena muestra de lo anterior. El caso, a mi juicio, muestra el comportamiento de los actores relevantes que participan en la discusión constitucional -aun de modo oblicuo. En tal sentido, es notable y sintomática la actitud expectante del Congreso Nacional en esta discusión; actitud que procura no salirse del espíritu hiper-presidencialista que la Constitución vigente fijara. Por su parte, la posición debilitada del Poder Judicial, como un cuerpo rígido de toscas interpretaciones legales, también cumple un papel fundamental. Finalmente, la pálida influencia de los actores sociales -en este caso, las organizaciones de mujeres- añade su magro sabor al insípido espectro del diálogo constitucional en nuestra práctica política. Quizá la narrativa que acompaña el debate sobre la legalidad de la droga sea uno de los caracteres más significativos de este desequilibrio.

Como señalé anteriormente, a pesar de la clave en derechos constitucionales que ha animado la retórica de organizaciones ciudadanas, los actores políticos (incluido el Poder Judicial) han eludido en lo posible hacerse cargo de ella.58 El uso de una narrativa que alude a derechos (fundamentales) para avanzar demandas sobre género y sexualidad no es inusual en la jurisprudencia constitucional. Un

\footnotetext{
${ }^{58}$ Quizá una notable excepción se produjo cuando el ex Presidente Lagos, tras el fallo de 2001 que declaró inconstitucional la política de su gobierno de autorizar la importación de la droga, señaló, en una entrevista radial, que "discutiendo muchas cosas de la píldora lo que estamos haciendo es evitar que mueran mujeres que quieren interrumpir el embarazo mediante el aborto". La oposición consideró que lo que el presidente hacía era una intromisión indebida en la competencia de los tribunales. Así, la entonces vicepresidenta del partido más importante de la derecha, reaccionó pidiéndole "al Presidente Lagos que, en un estado de derecho, respete el funcionamiento de las instituciones, porque aquí no podemos seguir gobernados sobre la base de sus propias opiniones personales. Hay instituciones que tienen que funcionar que han funcionado y que él tiene la obligación de respetar". Véase "UDI pide a Lagos respetar fallo por 'píldora del día después”", El Mostrador, 6 de septiembre de 2001, en

$<$ http://www.elmostrador.cl/modulos/noticias/constructor/noticia new.asp?id noticia=39439>
} 
estudio reciente llama a "examinar cómo estos derechos alternativos son conceptualizados; acaso difieren entre sí, se sobreponen; cuánto ayudan o dificultan la argumentación de demandas sobre aborto; qué distorsiones causan para tales argumentos, y qué consecuencias tienen para los derechos sexuales y reproductivos de las mujeres".59 Evidentemente, tal no es el propósito de este trabajo. No obstante ello, cabe al menos ensayar algunas ideas al respecto.

A pesar de que uno de los actores (actrices, en rigor) más relevantes de la disputa sobre la "píldora del día después" son las mujeres en edad fértil, su entendimiento de la discusión -en términos de derechos de autonomía- cedió el paso a la determinación de una disputada circunstancia fáctica la cual, a su vez, cerró la discusión con la bandera del derecho de los no nacidos (en 2001, sosteniéndose la primacía de estos derechos; en 2005, arguyendo la falta de pruebas sobre la pretensión a favor de los que están por nacer). Ni el Ejecutivo, defendiendo sus decisiones políticas, ni el Poder Judicial, escrutándolas, se han referido constitucionalmente a esto como un asunto de derechos de las mujeres. En una cultura legal formalista, como es la chilena, podría explicarse esta situación apelando a la inexistencia positiva del derecho de autonomía sexual y reproductiva -de allí, quizá, la idea del congresista Girardi de establecer un nuevo artículo 19 numero 2 en la Constitución. Sin embargo, creo que ésa es solo parte de la explicación, por cuanto parece claro que en la agenda gubernamental sí existe el reconocimiento del derecho de toda mujer a decidir libremente sobre su maternidad.

En marzo de 2005, el entonces Subsecretario de Salud, Antonio Infante, fue removido de su puesto tras anunciar que la anticoncepción de emergencia sería entregada a cualquier mujer que la solicitara, hubiese sido víctima de violación o no.60 El hecho provocó una reacción inmediata por parte de diversos actores que exigieron un pronunciamiento definitivo del Gobierno en la materia. Notablemente, éste tardó poco en llegar: no había cambio alguno en la política de distribución de la "píldora del día después". Ésta solo sería entregada de manera gratuita a las víctimas de violación, afirmación que se repitió incesantemente, no obstante las aseveraciones de diputados oficialistas de contar con documentos que acreditaban el cambio de política en el Ejecutivo (el cual había sido incluso comunicado a algunos servicios de salud). El avance de los derechos de las mujeres a decidir "si y cuándo" terminaba con la salida del funcionario estatal y con la inédita confesión del casi infalible Presidente de la República de "haberse mandado un condoro".61

Al comienzo del párrafo anterior, enfaticé que, a pesar de la narrativa escondida utilizada por el Gobierno, "toda" mujer debiera, en el entendimiento real del Ejecutivo, tener derecho a decidir. En esta manera de presentar el asunto, hay dos componentes; o, dicho de otro modo, dos derechos constitucionales cumpliendo sus roles: por una parte, está el derecho de autonomía (sexual y reproductiva) $y$, por la otra, hay una demanda de tratamiento igualitario. El primero, hemos visto, reposa en el derecho a decidir si tener o no hijos (y cuándo), mientras que el segundo componente consiste en el derecho de toda mujer a ejercer el derecho a decidir. En la medida en que la droga es vendida (y no distri-

${ }_{59}$ BAINES, Beverly y RUBIO-MARÍN, Ruth (eds.). The Gender of Constitutional Jurisprudente. Cambridge, Cambridge University Press, 2005, p. 17. La traducción es mía.

${ }^{60}$ Como expliqué antes, entonces el Ministerio de Salud entregaba la píldora a las víctimas de violación en razón de que resultaba discriminatorio que solo mujeres con capacidades económicas pudieran tener acceso a ella -obviamente, este argumento igualitario sirve también para justificar la distribución "a todo evento" de la píldora. El anuncio de Infante, así, buscaba informar que en adelante cualquier mujer que no contara con los medios necesarios para adquirir la píldora -fuera o no víctima de violación- tendría derecho de acceder a ella. Tal era la verdadera postura constitucional del Gobierno. Agradezco al ex subsecretario Infante el confirmarme personalmente esta información.

61 "Lagos reconoce que 'nos mandamos un condoro' con la píldora", El Mostrador.cl, en $<$ http://www.elmostrador.cl/modulos/noticias/constructor/noticia_new.asp?id_noticia=154931>. Lo usual por parte del Presidente Lagos no eran este tipo de coloquiales explicaciones, sino más bien frases que, en tercera persona, aludían a su capacidad e inteligencia, del tipo "el Presidente sabe lo que hace...". 
buida en forma gratuita), un importante número de mujeres no pueden acceder a ella, reproduciendo y perpetuando los esquemas de estratificación social que derivan de la maternidad no deseada.

La observación precedente me lleva a mi último punto, cual es, la necesidad por que exista coherencia normativa entre el discurso social y la comprensión que de ella misma tiene una comunidad interpretativa frente a los pronunciamientos que los funcionarios públicos producen en el seno de dicha comunidad. La aversión al diálogo que una determinada comunidad puede exhibir no solo debe rastrearse en un nivel horizontal -i.e., entre los diversos actores estatales, como el Parlamento o las cortes. De igual, o quizá mayor importancia, es la conversación que tiene lugar de modo vertical, esto es, entre grupos sociales y las autoridades públicas. En el lenguaje de Robert Cover, las comunidades de fe que existen en toda sociedad política y la ley imperial también se trenzan en una relación que construye sentidos y significados constitucionales -ya sea en una relación "jurispática”, que impide o anula la producción de entendimientos e interpretaciones alternativas del derecho; ya sea en una relación "jurisgenerativa", esto es, una relación por la cual el derecho es capaz, él mismo, de promover el desarrollo de interpretaciones constitucionales diferentes. 62

En mi opinión, existe una brecha entre la forma como los grupos sociales comprenden el problema aquí analizado y sus corolarios institucionales. Parece haber una división entre lo que algunos llaman "derecho constitucional" y "cultura constitucional"63, por cuanto si una cultura debiera contar de modo preferente en este caso (judicial y político) es, precisamente, la que ha estado ausente. Tal es, sabemos, el entendimiento de las propias mujeres, que son sujeto y objeto de la discusión y de sus implicaciones. Hemos visto que las cortes solo han ponderado los intereses de los potencialmente nacidos, dando la espalda a las demandas (basadas en derechos) de las mujeres. No critico los resultados, esto es, el fondo de las decisiones a favor y en contra de la píldora, sino la forma como a ellas llegan los tribunales: a pesar de la evidente colisión de derechos fundamentales, los tribunales no la reconocen y resuelven como si hubiese un solo interés involucrado. Ponderar todos los intereses comprometidos en una controversia constitucional no es solo una muestra de buena técnica judicial, sino además una necesidad para llegar a decisiones que puedan, a pesar del desacuerdo, ser consideradas legítimas. Un sistema y una práctica constitucional difícilmente pueden sostenerse si una mitad de él -la mitad "imperial", que tiene el poder de coerción-, suprime las narrativas, prácticas y retórica de la otra mitad. Al abrazar una aproximación maximalista, esto es lo que las cortes han hecho con las interpretaciones expuestas por el grupo de mujeres que aquí se hizo presente (con la excepción, sabemos, del pronunciamiento de la Corte de Apelaciones de diciembre de 2004). Y eso, ya lo he señalado, con distancia de lo que en los hechos acaecía.64

Como en toda democracia constitucional, la interpretación del texto político básico se hace "en medio de diversas opiniones en competencia acerca de su significado",65 pero la oposición entre cultura y derecho parece ser especialmente notable en nuestra práctica. Si, como entiende Post, "la

\footnotetext{
${ }^{62}$ COVER, op. cit. supra nota 52.

${ }^{63}$ POST, Robert C. "The Supreme Court, 2002 Term - Foreword: Fashioning the Legal Constitution: Culture, Courts, and Law”, en Harv. L. Rev, Vol. 117, 2003, p. 4 y ss.. Según él, "el derecho constitucional y la cultura se encuentran enlazados en una relación dialéctica, de modo que el derecho constitucional deriva de y al mismo tiempo regula la cultura [...] la Corte, en efecto, desarrolla y elabora el derecho constitucional en el contexto de un diálogo permanente con la cultura, de suerte que la cultura es inevitable y propiamente incorporada en el paquete del derecho constitucional" (Ibíd., p. 8). La traducción es mía.

${ }^{64}$ La prensa informaba que, en julio de 2004, 65,2\% de la población chilena aprobaba el uso de la píldora de anticoncepción de emergencia. El Mostrador.cl, en

$<\underline{\text { http:} / / \text { www.elmostrador.cl/modulos/noticias/constructor/noticia_new.asp?id_noticia }=137930>}$.

${ }^{65}$ SIEGEL. op. cit., supra nota 27, p. 350.
} 
cultura constitucional es el medio a través del cual el derecho constitucional toma forma" 66 , hace falta una mejor mediación entre el derecho y la cultura. La necesidad de construir significado(s) constitucional(es) de una manera dialógica clama por mayor apertura de parte del Poder Judicial. Solo entonces, tanto las autoridades con potestad pública como los grupos sociales pueden llevar adelante una empresa común de argumentar constitucionalmente sin recurrir a pretensiones disfrazadas. Ello representaría un avance en la consolidación de nuestra práctica democrática y, solo así, podría decirse con propiedad, y no a la manera acrítica al que nos hemos acostumbrado, que "las instituciones funcionan".

${ }^{66}$ POST. op. cit., supra nota 63, p. 77. 